\title{
Can You Identify the Microstructure?
}

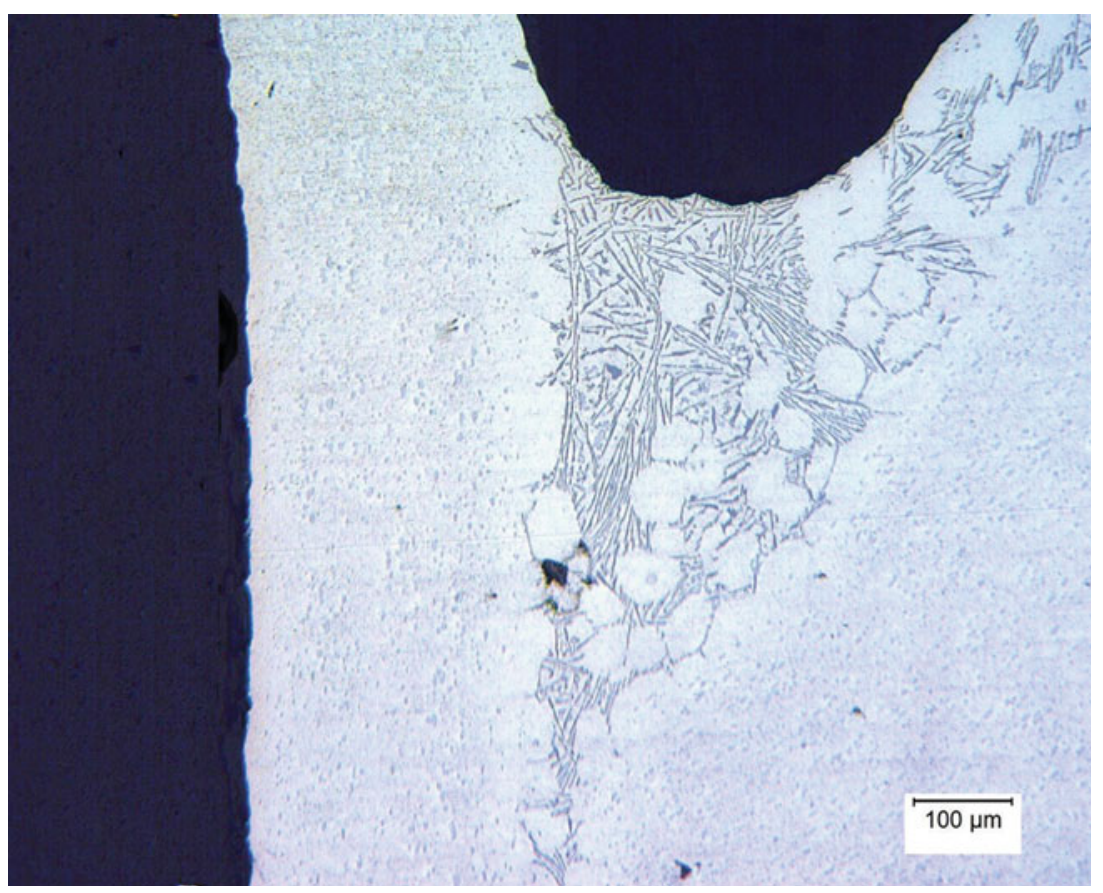

Describe the microstructure accurately and win an invitation to submit your own "Mystery Micrograph."

1. What is the material?

2. What type of joint and what base composition?

3. Can you guess the manufactured product? Clue: We probably all rely on at least one every day!

Winner and answer will appear in an upcoming issue.
Exceptional micrographs from winner submittals may be used on the journal cover.

Send your clear, brief description by e-mail to the MMA editor at Ryan.Deacon@jhuapl.edu. Entries should be titled: "MMA Mystery Micro 5."

Above micrograph submitted by Matt Welc, Product Evaluation Systems, Inc., Latrobe, Pa. 
Issue 3/4 Mystery Micrograph

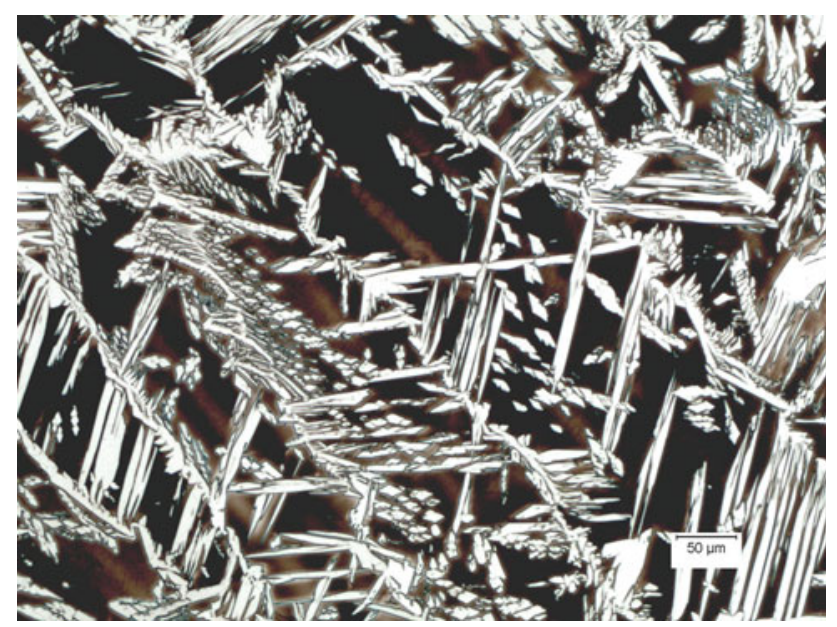

The microstructure of the Issue 3/4 Mystery Micrograph is ferrite (dark and brown) and austenite (white) in an ASTM S32205 Duplex Steel weld resulting from a gas tungsten arc welding (GTAW) process using ER 2209 filler metal and Beraha's etch with a slightly longer etch time than normal to darken ferrite from a blue coloration. 